\title{
Upaya Meningkatkan Kepekaan Sosial Melalui Layanan Konseling Kelompok Dengan Teknik Modeling pada MTs Al- Ikhwan Banjarmasin
}

\author{
D Ainun Heiriyah*, Sri Ayatani Hayati \\ Universitas Islam Kalimantan Muhammad Arsyad, Indonesia \\ @ainunheiriyah @gmail.com*
}

Submitted:
2020-06-24
Revised:
2020-08-11
Accepted:
2020-09-01
Copyright holder:
O Heiriyah, A., \& Ayatani, S, A. (2020)
This article is under:
CCC
How to cite:
Heiriyah, A., \& Ayatani, S, A. (2020). Upaya Meningkatkan
Kepekaan Sosial Melalui Layanan Konseling Kelompok
dengan Teknik Modeling pada MTs Al-Ikhwan
Banjarmasin. Bulletin of Counseling and Psychotherapy, 2(2).
Published by:
Kuras Institute
Journal website:
https://journal.kurasinstitute.com/index.php/bocp
E-ISSN:
2656-1050

\begin{abstract}
The objectives of this study were: (1) To determine the level of social sensitivity of students before being given group counseling services using modeling techniques to students, (2) To determine the level of social sensitivity of students after being given group counseling services with modeling techniques for students, (3) knowing How effective are group counseling services with modeling techniques in increasing social sensitivity in students. This study used experimental (non-parametric) methods and was a quasi experimental design using one group pre test and post test design. The subjects in this study were students who had low social sensitivity. Research Results (1) pretest score 64.14 in the medium category. (2) posttest score 89.85 high category (3) results of analysis of Wilcoxon Ztabel test data -2.371 with a significant level of $0.5 \%$, then $Z$ hitung $=0.839$. $Z$ hitung price $2.371<Z$ table 0.839 so that the alternative hypothesis $\mathrm{Ha}$ is accepted and Ho is rejected. Group counseling services with effective modeling techniques to increase students' social sensitivity.

KEYWORDS: social sensitivity; group counseling; modeling techniques
\end{abstract}

\section{PENDAHULUAN}

Kepekaan sosial penting ditanamkan semenjak kecil pada anak, agar kelak ia menjadi manusia dewasa yang peka dengan lingkungan sekitarnya. Adapun yang bertanggung jawab untuk menumbuhkan kepekaan sosial pada anak adalah orang tua. Namun bukan berarti orangtua semata penentunya, karena lingkungan juga turut memberikan andil. Kepekaan sosial (social sensitivity) secara sederhana dapat diartikan sebagai kemampuan seseorang untuk bereaksi secara cepat dan tepat terhadap objek atau situasi sosial tertentu yang ada disekitarnya.

Terdapat beragam kepekaan sosial diantaranya adalah berbagi dengan orang lain, bersedia membantu orang yang membutuhkan, berani meminta maaf apabila melakukan kesalahan, serta menghargai orang lain yang memiliki kondisi yang berbeda. Kepekaan sosial anak dengan mudah terlihat dalam gaya pergaulan masing-masing individu. Kepekaan sendiri harus dilatih sejak usia dini, karena pada usia tersebut anak masih mudah untuk menerima dan muda untuk diajari. Sehingga, ketika mereka telah besar nanti akan mudah untuk bersosialisasi di lingkungannya dan mudah bergaul dengan teman di sekitarnya. Jadi kepekaan sosial dapat diartikan sebagai sebuah tindakan dari seorang individu yang berasal dari dalam dirinya untuk ikut merasakan dan mudah terangsang atas 
setiap kejadian yang terjadi di sekelilingnya, baik itu tentang peristiwa menyedihkan atau peristiwa menyenangkan.

Layanan Konseling kelompok dengan teknik modeling diharapkan dapat meningkatkan bantuan kepada para peserta didik. Layanan konseling kelompok merupakan upaya bantuan untuk dapat memecahkan masalah siswa dengan memanfaatkan dinamika kelompok. Apabila dinamika kelompok dapat terwujud dengan baik maka anggota kelompok akan saling menolong, menerima dan berempati dengan tulus (Davis, 1983). Konseling kelompok merupakan wahana untuk menambah penerimaan diri dan orang lain, menemukan alternatif cara penyelesaian masalah dan mengambil keputusan yang tepat dari konflik yang dialaminya dan untuk meningkatkan tujuan diri, otonomi dan rasa tanggung jawab pada diri sendiri dan orang lain.

Di MTs Al-Ikhwan Banjarmasin masih terdapat siswa yang memiliki kepekaan sosial yang rendah hal ini berdasarkan penyebaran instrument DCM, Beberapa kepekaan sosial rendah tersebut meliputi perilaku: kurangnya kepedulian terhadap temannya yang terkena musibah, kurangnya kepedulian terhadap gotong royong dalam kebersihan lingkungan sekolah, kurangnya kepedualian siswa dalam membantu teman yang kurang mengerti dalam salah satu mata pelajaran yang sulit. Hal ini apabila dibiarkan, maka akan berdampak serius terhadap para siswa yang mengalami rendahnya kepekaan sosial terhadap orang disekitarnya.

Berdasarkan urian latar belakang tersebut, maka peneliti tertarik untuk melakukan penelitian dengan judul "Upaya Meningkatkan Kepekaan Sosial Melalui Layanan Konseling Kelompok Dengan Teknik Modeling Pada MTs Al-Ikhwan Banjarmasin.

\section{METODE}

Populasi dalam penelitian ini merupakan siswa kelas XI AP di SMK Negeri 1 Pemulutan. sebanyak 30 siswa dan untuk pengambilan sampel, penelitian menggunakan sampel bertujuan peneliti mengambil 10 siswa sebagai sampel berdasarkan kategori skor 5 siswa terendah dan 5 siswa berada di kategori skor tertinggi hasil dari skor angket.

Jenis penelitian yang digunakan adalah penelitian eksperimental (non parametris). Sugiyono (2013) menyatakan bahwa "penelitian eksperimen diartikan sebagai metode penelitian yang digunakan untuk mencari pengaruh perlakuan tertentu terhadap yang lain dalam kondisi yang terkendalikan". Alasan peneliti menggunakan pola eksperimen ini adalah untuk melihat akibat dari suatu perlakuan (Konseling Kelompok Teknik Modeling) terhadap variabel yang lain (Kepekaan Sosial). Metode one group pre test and post test design berarti sampel diberikan skala penilaian sebelum eksperimen (pre-test) dan sesudah ekperimen (post-test), dengan begitu hasilnya lebih akurat karena membandingkan dengan keadaan sebelumnya diberi perlakuan menurut (Sugiono, 2013).

Rancangan pelaksanaan penelitian ekperimen di MTs Al-Ikhwan Banjarmasin ini adalah sebagai berikut: 1. (Pretest): Melakukan pretest menggunakan skala kepekaan sosial sebelum mendapatkan perlakuan layanan konseling kelompok dengan teknik modelling. hasil pre-test ini akan menjadi bahan perbandingan dengan post-test yang akan dilakukan setelah pemberian perlakuan yaitu layanan konseling kelompok dengan teknik modelling; 2. (Treatmen) Perlakuan: Memberikan perlakuan (treatment) menggunakan layanan konseling kelompok dengan teknik modelling. Akan dilaksanakan 1 kali pertemuan kurang lebih 45 menit; dan 3. (Posttest): Tujuan dari dilakukannya posttest adalah untuk mengetahui tingkat keberhasilan selama dilakukan treatmen dan mengetahui peningkatan kepekaan sosial siswa pada MTs Al-Ikhwan Banjarmasin. 
Populasi dalam penelitian adalah semua siswa MTs Al-Ikhwan Banjarmasin. yang berjumlah 154 siswa yang terdiri dari: kelas VII ruang A dan B; kelas VIII ruang A,B, dan C; dan kelas IX ruang A, $B$, dan $C$. Teknik pengambilan sampel menggunakan proposive sampling, karena sampel sampel yang akan diambil adalah siswa yang memiliki kepekaan sosial yang rendah dari yang lain yang terdapat dalam populasi. Proposive sampling merupakan teknik pengambilan sampel yang mempunyai tujuan, yaitu untuk mengambil siswa yang kepekaan sosialnya rendah dari siswa lain. adapun sample penelitian ini berjumlah 7 orang siswa kelas VIII.

Menurut Sugiono (2013) Variabel bebas adalah merupakan variabel yang mempengaruhi atau menjadi sebab perubahannya dan timbulnya variabel dependen (terikat). Variabel bebas pada penelitian ini adalah layanan konseling kelompok $\left(X_{1}\right)$ dan teknik modelling $\left(X_{2}\right)$. Layanan konseling kelompok dengan teknik modelling akan mempengaruhi kepekaan sosial (variabel terikat) agar mengalami perubahan.

Menurut Sugiono (2013) Variabel terikat adalah merupakan variabel yang dipengaruhi atau yang menjai akibat, karena adanya variabel bebas. Variabel terikat dalam penelitian ini adalah kepekaan sosial. Kepekaan sosial dipengaruhi oleh konseling kelompok (variabel bebas) agar dapat mengalami perubahan pada kepekaan sosial. Variabel bebas disimbolkan dengan X. Dalam penelitian ini variabel bebas yang mempengaruhi perubahan variabel terikat. Variabel terikat disimbolkan dengan Y. Dalam penelitian ini variabel terikat yang dipengaruhi oleh variabel bebas. Di bawah ini dapat dilihat hubungan antara variabel bebas dan terikat:

\begin{tabular}{c|c|c}
\hline $\begin{array}{c}\text { Layanan Konseling } \\
\text { kelompok dengan } \\
\text { teknik modelling } \\
\mathrm{X}\end{array}$ & & $\begin{array}{c}\text { Meningkatkan } \\
\text { Kepekaan Sosial } \\
\mathrm{Y}\end{array}$ \\
\hline
\end{tabular}

Gambar 1. Variabel Penelitian

Menurut Arikunto (2013) prosedur yang ditempuh adalah: 1) perencaan; 2) penulisan butir soal; 3) penyuntingan; 4) uji coba; 5). analisis hasil; 6) revisi; dan 7) instrumen jadi. Setelah mengetahui langkah-langkah dalam penyusunan instrumen penelitian, maka selanjutnya adalah membahas mengenai kisi-kisi instrumen dengan menyusun instrument secara utuh beserta lembar jawabannya. Dalam penelitian ini menggunakan metode pengumpulan data berupa skala psikologi. Data yang akan dianalisis dan diukur diperoleh langsung dari sampel responden yang menjawab semua item instrument. Penggunaan instrument dimaksudkan untuk memperoleh data tentang meningkatkan kepekaan sosial. Instumen yang digunakan adalah skala likert yang terdiri dari 4 pilihan.

Arikunto (2013) validitas adalah suatu ukuran yang menunjukkan tingkat-tingkat kevalidan atau kesahihan suatu instrument. Validitas merupakan derajat ketepatan antara data yang terjadi pada objek penelitian dengan daya yang dilaporkan peneliti. Dengan demikian data yang valid adalah data yang tidak berbeda antara data yang dilaporkan peneliti dengan data yang sesungguhnya terjadi pada penelitian. Untuk menguji validitas instrument penelitian ini, peneliti menggunakan pengujian validitas konstrak (Construct validity) dilakukan dengan Pearson Correlation, yaitu dengan membandingkan $\mathrm{R}$ tabel dan $\mathrm{R}$ hitung.

Maka Peneliti menggunakan analisis butir yaitu mengkorelasikan skor per-item dengan skor total. Rumus yang digunakan adalah korelasi product moment yang dikemukakan oleh Karl Pearson (Arikunto, 2013) sebagai berikut: 


$$
\mathrm{rxy}=\frac{n \sum x Y-\left(\sum X\right)\left(\sum Y\right)}{\sqrt{\left.\left\{N \sum x^{2}-\left(x^{2} x^{2}\right)\right\}\left\{N \sum Y^{2}-\sum Y\right)^{2}\right\}}}
$$

Menurut Arikunto (2013) Reliabilitas menunjukkan pada satu pengertian bahwa suatu instrument cukup dapat dipercaya untuk digunakan sebagai alat pengumpul data karena instrument tersebut sudah baik. Instrumen yang baik tidak akan bersifat tendensius mengarahkan responden untuk memilih jawaban-jawaban tertentu. Instrumen yang sudah dapat dipercaya, yang reliabel akan menghasilkan data yang dapat dipercaya juga. Apabila datanya memang benar sesuai dengan kenyataannya, maka berapa kali pun diambil, tetap akan sama. Uji reabilitas instrumen pada penelitian ini menggunakan rumus Cronbach'salpha $(\alpha)$ secara statistik memakai Microsoft Exel dan aplikasi SPSS. Untuk menguji validitasnya angket yang dibuat agar reliabel akan menghasilkan data yang dapat dipercaya. Untuk mengukur reliabilitas instrument dalam penelitian ini menggunakan rumus Alpha yaitu (Arikunto, 2013)

$$
\mathrm{r}_{11}=\left(\frac{K}{K-1}\right)\left(1-\frac{\sum \sigma \mathrm{b} 2}{\sigma 2 \tau}\right)
$$

Keterangan:

$r_{11}$ : Reliabilitas instrument

$\sum \sigma \mathrm{b} 2$ : Jumlah varian butir

$k$ : Banyaknya butir pertanyaan atau banyaknya soal $\sigma 2 \tau$ : Varian total

Peneliti menggunakan analisis deskriptif persentase untuk mengetahui gambaran kepekaan sosial siswa sebelum dan sesudah diberi layanan konseling kelompok dengan teknik modelling. Rentang peneliaian pada skala kepekaan sosial dengan menggunakan rentang skor positif 4-1 dan skor negative 1-4 yang mewakili 3 kriteria kepekaan sosial yaitu, tinggi (87-116), sedang (58-87), dan rendah (29-58). Sehingga interval kriteria tersebut dapat dilihat sebagai berikut:

Teknik analisis data yang digunakan dalam penelitian ini menggunakan rumus uji Wilcoxon yaitu dengan cara membandingkan hasil dari pre-test dan post-test dengan tabel bantu untuk test Wilcoxon (Sugiyono, 2013). Sampel yang diteliti dalam penelitian ini kurang dari 25 maka cara penghitungan yang digunakan adalah membandingkan jenjang terkecil dari pre test dan post test dengan tabel harga-harga kritis dalam tes Wilcoxon.

Dasar analisis dengan Wilcoxon adalah bahwa penelitian ini objek yang diteliti hanya berjumlah 7 orang siswa, sehingga tidak memenuhi kurva normal jadi termasuk non parametric, dengan menggunakan Wilcoxon Matched Pairs Test. Uji Wilcoxon digunaan dengan mencari perbedaan mean pretest dan posttest.

\section{HASIL DAN PEMBAHASAN}

Pretest diberikan kepada sample penelitian 7 orang siswa dengan menggunakan skala kepekaan sosial. Rincian pelaksanaan kegiatan layanan konseling kelompok dengan teknik modeling untuk meningkatkan kepekaan sosial siswa MTs Al Ikhwan Banjarmasin dapat dilihat pada tabel 2.

Hasil analisis deskriptif kuantitatif merupakan uraian mengenai hasil penelitian yang berdasarkan kepada hasil analisis perhitungan pretest atau perhitungan kondisi awal kepekaan sosial siswa sebelum diberikan perlakuan konseling kelompok dengan teknik modeling dan hasil analisis perhitungan posttest atau hasil perhitungan kondisi akhir kepekaan sosial siswa setelah diberikan perlakuan berupa layanan konseling kelompok dengan teknik modelling. Selain itu untuk melengkapi hasil analisis kuantitatif ini juga akan diuraikan mengenai hasil pretest, treatmen konseling kelompok dengan teknik modelling, dan hasil perbandingan pretest dan posttest melalui uji Wilcoxon. 
Tabel 1. Rincian Kegiatan Pretest, Treatmen dan Posttest

\begin{tabular}{llll}
\hline Kegiatan & Materi & Tempat & Waktu \\
\hline Pretest & Skala kepekaan sosial & $\begin{array}{l}\text { Ruang kelas XII MTs Al- } \\
\text { Ikhwan Banjarmasin }\end{array}$ & 45 menit \\
$\begin{array}{l}\text { Perlakuan (Treatmen) } \\
\text { layanan konseling } \\
\text { kelompok dengan teknik } \\
\text { modelling }\end{array}$ & $\begin{array}{l}\text { Memahami pentingnya } \\
\text { hidup bersosial serta } \\
\text { berperilaku yang } \\
\text { bertanggung jawab dalam } \\
\text { masyarakat }\end{array}$ & $\begin{array}{l}\text { Panggung MTs Al-Ikhwan } \\
\text { Bajarmasin }\end{array}$ & 45 menit \\
Posttest & Skala kepekaan sosial & $\begin{array}{l}\text { Panggung MTs Al-Ikhwan } \\
\text { Banjarmasisn }\end{array}$ & 45 menit \\
\hline
\end{tabular}

Gambaran Tingkat Kepekaan Sosial Siswa Sebelum Diberikan Layanan Konseling Kelompok Dengan Teknik Modeling

Sebelum peneliti melakukan treatmen layanan konseling kelompok dengan teknik modelling pada siswa. Peneliti perlu mengetahui kondisi awal kepekaan sosial dengan memberikan pretest. Instrumen diberikan oleh peneliti kepada 7 orang siswa. berikut hasil rekapilasi hasil pretest siswa pada tabel 2.

Tabel 2. Hasil Pretest Kepekaan Sosial Siswa MTs Al-Ikhwan Banjarmasin

\begin{tabular}{lll}
\hline Kode Responden & Skor & Kategori \\
\hline $100.01 \mathrm{AB}$ & 63 & Sedang \\
$100.02 \mathrm{AC}$ & 64 & Sedang \\
$100.03 \mathrm{AD}$ & 69 & Sedang \\
$100.04 \mathrm{AE}$ & 77 & Sedang \\
$100.05 \mathrm{AF}$ & 67 & Sedang \\
$100.06 \mathrm{AG}$ & 56 & Rendah \\
$100.07 \mathrm{AH}$ & 53 & Rendah \\
Rata-rata & 64,14 & Sedang \\
\hline
\end{tabular}

Dari tabel 2, dapat dilihat bahwa 7 orang siswa hasil dari pretest dengan skor 53 dan skor 56 dalam kategori Rendah Kepekaan Sosialnya terdiri atas 2 orang siswa. Sedangkan skor 63, 64, 69, 67, dan skor 77 kategori Sedang Kepekaan sosialnya terdiri atas 5 orang. Rata-rata hasil pretest kepekaan sosial siswa MTs Al-Ikhwan Banjarmasin dengan rata-rata skor 64,14 dengan kategori Sedang. Gambaran pretest tersebut apabila divisualkan dalam bentuk grafik dapat dilihat pada gambar 2 .

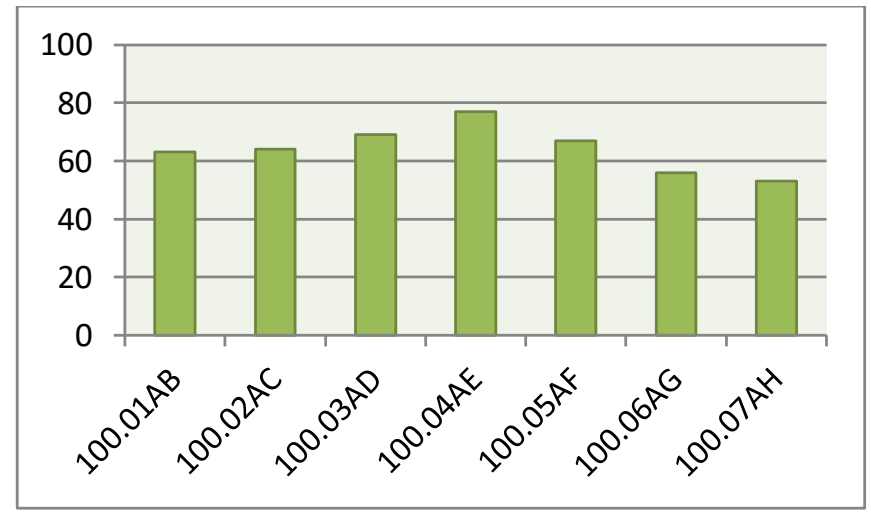

Gambar. 2

Grafik Hasil Pretest Kepekaan Sosial Siswa Al-Ikhwan Banjarmasin

Pada gambar 2 dapat dilihat hasil grafik pretest kepekaan sosial siswa sebelum diberikan treatmen konseling kelompok dengan teknik modeling masing-masin sebagai berikut: 
1. 100.01AB dengan skor 63 berkategori sedang

2. 100.02AC dengan skor 64 berkategori sedang

3. 100.03AD dengan skor 69 berkategori sedang

4. 100.04AE dengan skor 77 berkategori sedang

5. 100.05AF dengan skor 67 berkategori sedang

6. 100.06AG dengan skor 56 berkategori rendah

7. 100.07AH dengan skor 53 berkategori rendah

Tingkat Kepekaan Sosial Siswa Sesudah Diberikan Layanan Konseling Kelompok Dengan Teknik Modeling

Setelah diberikan perlakuan yaitu diberikannya layanan konseling kelompok dengan teknik modelling kepada 7 oran siswa MTs Al-Ikhwan Banjarmasin. Hasil yang diperoleh disajikan dalam bentuk tabel 3.

Tabel 3. Hasil Posttest Kepekaan Sosial Siswa MTs Al-Ikhwan Banjarmasin

\begin{tabular}{lll}
\hline Kode Responden & Skor & Kategori \\
\hline $100.01 \mathrm{AB}$ & 94 & Tinggi \\
$100.02 \mathrm{AC}$ & 83 & Sedang \\
$100.03 \mathrm{AD}$ & 80 & Sedang \\
$100.04 \mathrm{AE}$ & 85 & Sedang \\
$100.05 \mathrm{AF}$ & 96 & Tinggi \\
$100.06 \mathrm{AG}$ & 97 & Tinggi \\
$100.07 \mathrm{AH}$ & 94 & Tinggi \\
Rata-rata & 89,85 & Tinggi \\
\hline
\end{tabular}

Dari tabel di atas dapat dilihat bahwa 7 orang siswa hasil dari posttest dengan skor 80, 83, dan 85 kategori Sedang Kepekaan Sosialnya terdiri atas 3 orang siswa. Sedangkan skor 94, 96, dan 97 kategori tinggi Kepekaan Sosialnya terdiri atas 4 orang. Rata-rata hasil posttest kepekaan sosial siswa MTs Al-Ikhwan Banjarmasin dengan rata-rata skor 89,85 dengan kategori Tinggi. Gambaran posttest tersebut apabila divisualkan dalam bentuk grafik dapat dilihat pada gambar 3 .

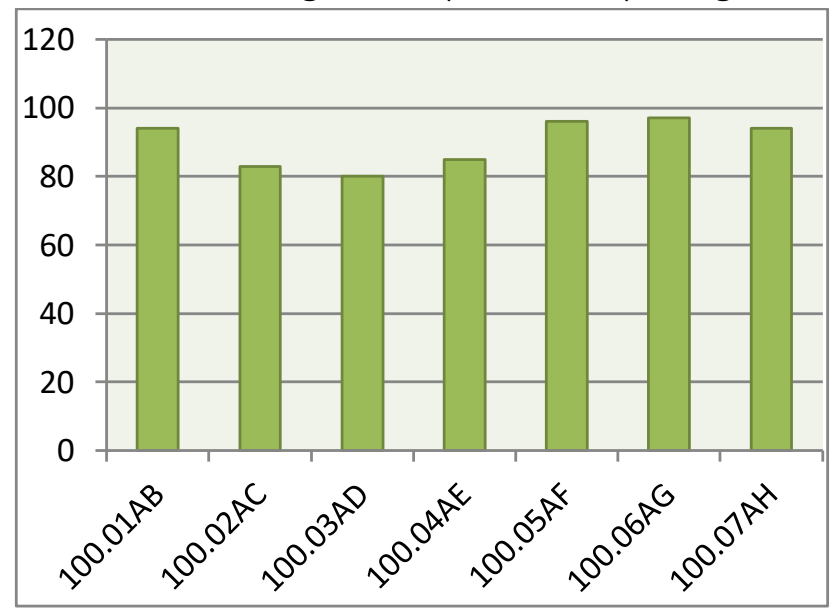

Gambar 3. Grafik Hasil Posttest Kepekaan Sosial Siswa Al-Ikhwan Banjarmasin

Pada gambar 3 tersebut dapat dilihat hasil grafik postest kepekaan sosial siswa sesudah diberikan treatmen konseling kelompok dengan teknik modelling dengan skor sebagai berikut:

1. $100.01 \mathrm{AB}$ dengan skor 94 berkategori tinggi

2. 100.02AC dengan skor 83 berkategori sedang

3. 100.03AD dengan skor 80 berkategori sedang

4. 100.04AE dengan skor 85 berkategori sedang

5. 100.05AF dengan skor 96 berkategori tinggi 
6. 100.06AG dengan skor 97 berkategori tinggi

7. 100.07AH dengan skor 94 berkategori tinggi

Efektivitas Layanan Konseling Kelompok Dengan Teknik Modeling Untuk Meningkatkan Kepekaan Sosial

Adanya perbandingan kepekaan sosial siswa MTs Al-Ikhwan Banjarmasin sebelum dan sesudah diberikan treatmen layanan konseling kelompok dengan teknik modelling. Hasil perbandingan ni dijelaskan secara rinci pada tabel 4.

Tabel 4. Perbandingan Hasil Pretest dan Hasil Posttest

\begin{tabular}{lll}
\hline Sampel Penelitian & Pretest & Posttest \\
\hline $100.01 \mathrm{AB}$ & 63 & 94 \\
$100.02 \mathrm{AC}$ & 64 & 83 \\
$100.03 \mathrm{AD}$ & 69 & 80 \\
$100.04 \mathrm{AE}$ & 77 & 85 \\
$100.05 \mathrm{AF}$ & 67 & 96 \\
$100.06 \mathrm{AG}$ & 56 & 97 \\
$100.07 \mathrm{AH}$ & 53 & 94 \\
Rata-rata & 64,14 & 89,85 \\
\hline
\end{tabular}

Berdasarkan tabel di atas, rata-rata skor kepekaan sosial siswa sebelum mengikuti treatmen adalah 64, 14 dan setelah mengikuti treatmen meningkat menjadi 89,85. Tabel di atas telah menjelaskan bahwa terjadi peningkatan dari sebelum dengan setelah diberikan perlakuan (treatmen) layanan konseling kelompok dengan teknik modeling. Hasil pretest dan posttest ini juga disajikan dalam bentuk virtul gambar grafik di bawah ini:

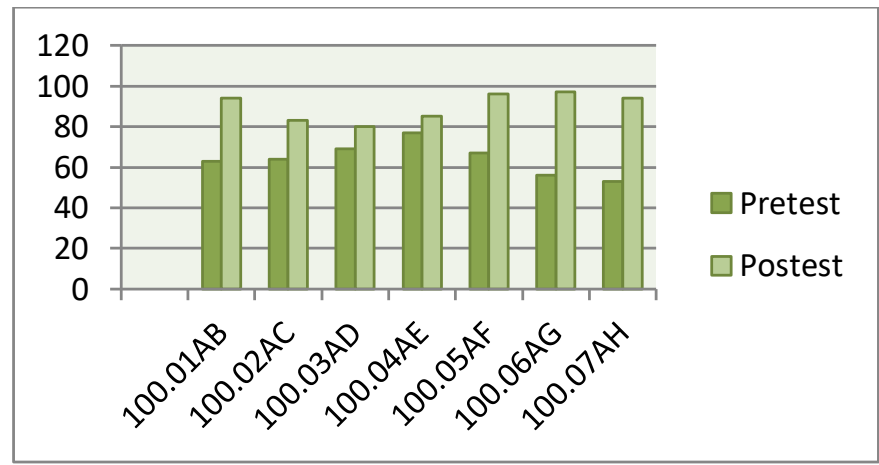

Gambar. 3 Grafik Perbandingan Hasil Pretest dan Hasil Posttest

Pada gambar 3 tersebut dapat dilihat grafik hasil pretest dan posttest kecemasan sosial siswa sebelum diberikan treatmen dan sesudah diberikan treatmen layanan konseling kelompok dengan teknik modelling. Masing-masing responden memilki peningkatan sebagai berikut:

1. 100.01AB dari skor 63 kategori sedang meningkat menjadi skor 94 kategori tinggi;

2. 100.02AC dari skor 64 kategori sedang meningkat menjadi skor 83 kategori sedang;

3. 100.03AD dari skor 69 kategori sedang meningkat menjadi skor 80 kategori sedang;

4. 100.04AE dari skor 77 kategori sedang meningkat menjadi skor 85 kategori sedang;

5. 100.05AF dari skor 67 kategori sedang meningkat menjadi skor 96 kategori tinggi;

6. 100.06AG dari skor 56 kategori rendah meningkat mejadi skor 97 kategori tinggi;

7. 100.07AH dari skor 53 kategori rendah meningkat menjadi skor 94 kategori tinggi; 
Tabel. 5 Hasil Uji Hopotesis

\begin{tabular}{lrr}
\hline \multicolumn{2}{c}{ Test Statistics $^{\mathrm{a}}$} & \\
\hline Z & Posttest-Pretest & \\
Asymp. Sig (2-tailed) & $-371^{\mathrm{b}}$ \\
a. Wilcoxon Signed Ranks Test &, 018 \\
b. Based on negative rank & \\
\hline
\end{tabular}

Tabel 5. terlihat bahwa hasil analisis data uji Wilcoxon dengan menggunakan SPSS V.22 diperoleh $Z_{\text {hitung }}$ sebesar $-2.371^{\mathrm{b}}$ dengan Asymp.sig. (2-tailed) sebesar 0,018. Nilai $Z_{\text {hitung }}$ akan dibandingkan dengan $Z_{\text {tabel }}$ dengan taraf kesalahan sebesar $5 \%(0,05)$. Apabila didilihat dari $Z_{\text {tabel }}$ dengan taraf signifikan 0,5\% maka $Z_{\text {hitung yaitu: 0,839. Harga }} Z_{\text {hitung }}-2.371<Z_{\text {tabel }} 0,839$ sehingga hipotesis alternative Ha diterima dan Ho ditolak. Hal ini bermakna layanan konseling kelompok dengan teknik modelling efektif untuk meningkatkan kepekaan sosial siswa. Berdasarkan hasil analisis data menunjukkan bahwa kepekaan sosial siswa MTs Al-Ikhwan Banjarmasin dapat ditingkatkan melalui layanan konseling kelompok dengan teknik modelling. Adapun pembahasan dari hasil analisis tersebut dibahas pada bagian berikut ini:

Kepekaan sosial siswa MTs Al-Ikhwan Banjarmasin tergolong kategor rendah yang terdiri atas 7 orang siswa. 2 orang berkategori rendah dan 5 orang berkategori sedang. Berdasarkan pengamatan pada awal pertemuan melakukan kegiatan konseling kelompok dengan teknik modelling ketujuh orang siswa memang memiliki perilaku tidak peduli dengan keadaan yang terjadi di lingkungan sekolah dan tidak peduli terhadap teman yang memiliki masalaah. Hal ini membuktikan bahwa kepekaan sosial pada setiap anggota belum muncul. Mereka masih acuh terhadap lingkungan di sekitarnya (sekolah).

Setelah mengetahui hasil pretest siswa MTs Al-Ikhwan Banjarmasin dengan kategori sedang, maka siswa selanjutnya diberikan treatmen dengan tema yang telah ditentukan. treatmen ini berjalan selama 45 menit bertempat di panggung MTs Al-Ikhwan Banjarmasin. Setelah diberikan perlakuan berupa layanan konseling kelompok dengan teknik modelling dengan tema "memahami pentingnya hidup bersosial serta berperilaku yang bertanggung jawab dalam masyarakat" maka peneliti melakukan posttest kepada 7 orang siswa yang telah mengikuti (treatmen) layanan konseling kelompok dengan teknik modelling. Analisis hasil posttest menunjukkan adanya peningkatan kepekaan sosial siswa yang telah mengikuti layanan konseling kelompok dengan teknik modelling dengan skor rata-rata 89,85 dengan kategori tinggi. Hal ini mengindikasikan sudah ada peningkatan dalam kepekaan sosial yang dimiliki siswa setelah adanya layanan konseling kelompok dengan teknik modelling mencapai skor rata-rata meningkat dengan kategori tinggi. Sebagaimana disebutkan oleh Isnaeni (2017) Kepekaan sosial merupakan kemampuan untuk merasakan dan mengamati reaksireaksi atau perubahan orang lain yang ditunjukkannya baik secara verbal maupun nonverbal. Seseorang yang memiliki kepekaan sosial yang tinggi akan mudah memahami dan menyadari adanya reaksi-reaksi tertentu dari orang lain, entah reaksi tersebut positif atau pun negatif.

Adanya kepekaan sosial akan membuat seseorang dapat bersikap dan bertindak yang tepat terhadap orang lain yang ada disekitarnya. Menurut Mu'in (2011) Kepedulian adalah sifat yang membuat pelakunya merasakan apa yang dirasakan orang lain, mengetahui bagaimana rasanya jadi orang lain, kadang ditunjukkan dengan tindakan memberi atau terlibat dengan orang lain tersebut. Kepedulian sosial merupakan bentuk tindakan yang positif yang dilakukan dengan sukarela atas inisiatif sendiri tanpa adanya paksaan dari pihak luar yang dilakukan semata-mata hanya untuk 
membantu dan menolong orang lain tanpa mengharapkan suatu imbalan. Selain itu, kecemasan sangat berpengaruh untuk optimalisasi peforma seseorang dalam berbagai konteks kehidupan (Fadliyah \& Hernisawati, 2020)

Orang yang memiliki kepekaan sosial pastinya akan menjadi pribadi yang asyik untuk diajak bergaul. Banyak teman yang akan suka kepadanya dan merasa nyaman bersamanya. Dengan demikian Guru BK/ konselor yang bekerja di sekolah MTs Al-Ikhwan Banjarmain dapat membantu siswa dalam menumbuhkan kepekaan sosial terhadap teman dan lingkungan sekitar (sekolah) melalui layanan konseling kelompok dengan teknik modeling.

\section{KESIMPULAN}

Berdasarkan hasil penelitian upaya meningkatkan kepekaan sosial siswa melalui layanan konseling kelompok dengan teknik modelling pada MTs Al-Ikhwan Banjarmasin disimpulkan bahwa. Tingkat kepekaan sosial siswa sebelum diberikan layanan konseling kelompok dengan teknik modelling tergolong kategori sedang $(64,14)$, tingkat kepekaan sosial siswa sesudah diberikan layanan konseling kelompok dengan teknik modelling tergolong kategori tinggi $(89,85)$. Hasil analisis data uji Wilcoxon dengan menggunakan SPSS V.22 diperoleh Zhitung sebesar -2.371 $\mathrm{b}$ dengan Asymp.sig. (2tailed) sebesar 0,018. Dengan menggunakan taraf kesalahan 5\% (0,05), maka Zhitung yaitu: $-2.371<$ $Z_{\text {tabel }} 0,839$ sehingga hipotesis alternative $\mathrm{Ha}$ diterima dan Ho ditolak. Hal ini bermakna bahwa layanan konseling kelompok dengan teknik modelling efektif untuk mengingkatkan kepekaan sosial siswa. Selanjutnya penting bagi peneliti diharapkan dapat menambah pengetahuan dalam memahami secara mendalam dan lebih komprehensif tentang pelaksanaan yang meneliti tentang upaya meningkatkan kepekaan sosial melalui layanan konseling kelompok dengan teknik modeling.

\section{DAFTAR PUSTAKA}

Arikunto, Suharsimi. (2013). Prosedur Penelitian Suatu Pendekatan Praktik. Jakarta: Rineka Cipta.

Bakar, A., Luddin, M. (2010). Dasar-Dasar Konseling Tujuan Teori dan Praktik. Bandung: Cita Pustaka Media Perintis.

Davis, M. H., (1983) Measuring Individu Differences in Empaty: Evidence for a Multidimentional Approach. Journal of Personality and Sosial Phsychology. 144 (2): 126-133.

Erford, Breadley T. (2016). 40 Teknik Yang Harus Diketahui Setiap Konselor edisi kedua. Yogyakarta: Pustaka Pelajar.

Fadliyah, J., \& Hernisawati, H. (2020). Penerapan Bimbingan Kelompok Berbasis Lalaran untuk Mengatasi Kecemasan terhadap Hafalan Santri Di Pondok Pesantren. Bulletin of Counseling and Psychotherapy, 2(1), 20-26

Folastri, Sisca, dkk. (2016). Prosedur Layanan Bimbingan dan Konseling Kelompok. Bandung: Muhajid Press.

Mu'in, Fathul. (2011). Pendidikan Karakter Konstruksi Teoretik \& Praktik. Yogyakarta: Ruzz Media.

Kementrian Pendidikan dan Kebudayaan Republik Indonesia. (2016). Pedoman Bimbingan dan Konseling pada Pendidikan Dasar dan Menengah. Jakarta: tnp.

Komalasari, G., Wahyuni, E., Karsih. (2011). Teori dan Teknik Konseling. Jakarta Barat: Permata Putri Media.

Roshita, Ita. (2014). Meningkatkan Kedisiplinan Siswa Melalui Layanan Bimbingan Kelompok dengan Teknik Modeling. Jurnal Penelitian Tindakan Kelas, (16) 2.

Sugiyono. (2013). Metode Penelitian Kuantitatif, Kualitatif dan R\&D. Bandung: Alfabeta.

Sutoyo, Anwar. (2014). Pemahaman Individu. Observasi, Cheklist, Interviu, Kuesioner, Sosiometri. Edisi Revisi. Cetakan I. Yogyakarta: Pustaka Pelajar. 
Purnamasari, L., Ratna. (2012). Teknik-Teknik Konseling. Semarang: Buku Ajar BK UNNES.

Prayitno. (1995). Layanan Bimbingan dan Konseling Kelompok Dasar dan Profil. Padang: Ghalia Indonesia. 